\title{
Analytic philosophy and its synoptic commission: towards the epistemic end of days
}

Link to publication record in Manchester Research Explorer

\section{Citation for published version (APA):}

MacBride, F. (2014). Analytic philosophy and its synoptic commission: towards the epistemic end of days. In A. O'Hear (Ed.), Philosophical Traditions (pp. 221-236). (Royal Institute of Philosophy supplements). Cambridge University Press . http://dx.doi.org/10.1017/S1358246114000095

\section{Published in:}

Philosophical Traditions

\section{Citing this paper}

Please note that where the full-text provided on Manchester Research Explorer is the Author Accepted Manuscript or Proof version this may differ from the final Published version. If citing, it is advised that you check and use the publisher's definitive version.

\section{General rights}

Copyright and moral rights for the publications made accessible in the Research Explorer are retained by the authors and/or other copyright owners and it is a condition of accessing publications that users recognise and abide by the legal requirements associated with these rights.

\section{Takedown policy}

If you believe that this document breaches copyright please refer to the University of Manchester's Takedown Procedures [http://man.ac.uk/04Y6Bo] or contact uml.scholarlycommunications@manchester.ac.uk providing relevant details, so we can investigate your claim.

\section{OPEN ACCESS}




\title{
ANALYTIC PHILOSOPHY AND ITS SYNOPTIC COMMISSION: TOWARDS THE EPISTEMIC END OF DAYS
}

Fraser MacBride

Pre-publication Copy. Published in Royal Institute of Philosophy Supplement, 74, 2014, pp. 221-36, Cambridge University Press.

DOI: http://dx.doi.org/10.1017/S1358246114000095)

\begin{abstract}
There is no such thing as 'analytic philosophy', conceived as a special discipline with its own distinctive subject matter or peculiar method. But there is an analytic task for philosophy that distinguishes it from other reflective pursuits, a global or synoptic commission: to establish whether the final outputs of other disciplines and common sense can be fused into a single periscopic vision of the Universe. And there is the hard-won insight that thought and language aren't transparent but stand in need of analysis - a recent variation upon the abiding philosophical theme that we need to get behind appearances to tell the ultimate truth about reality- an insight that threatens to be lost once philosophers appeal to intuitions.
\end{abstract}

\section{Introduction}

What is analytic philosophy? It doesn't have a subject matter to call its own. You can get analytic about more or less anything. So there's no circumscribed list of things that analytic philosophy is really about as opposed to things it really isn't. If it's about anything it's about everything. And despite its name, analytic philosophy has no distinctive method either. Not all analytic philosophers commit themselves to a programme of analysis, whether of language or thought, and even if they do what they have in mind to do is often very different. Some analytic philosophers make it their business to analyse words and phrases of the languages we already speak whilst others dedicate themselves to inventing new languages that improve upon the old ones. When we stand back and really look at it, there seems nothing to constrain our enquiries, curb our excesses. Like Kurtz in Joseph Conrad's Heart of Darkness - upstream, beyond civilizing influences - analytic philosophy, or so it appears, 'takes place in an impalpable greyness, with nothing underfoot, with nothing around, without spectators, without 
clamour, without glory, without the great desire of victory, without the great fear of defeat, in a sickly atmosphere of tepid scepticism, without much belief in your own right, and still less in that of your adversary'. As Marlow, the narrator of Heart of Darkness, reflects 'If such is the form of ultimate wisdom, then life is a greater riddle than some of us think it to be'. No wonder Kurtz cried out before he expired, 'The horror! The horror!'

Analytic philosophers are confronted by a cultural predicament. Society is impatient with them whilst they are impatient with each other. Everybody wants something palpable to reach out and touch, nobody wants to be awash in a sea of grey scepticism, but analytic philosophers have been unable to supply solid, definitive answers. This impatience has its source in a misconception about philosophy itself, about what it can be expected to have achieved at this point in history, an impatience no doubt fuelled by the demands of late capitalism that lead us to expect rapid results.

\section{Cutting the Analytic Knot}

Lacking a distinctive subject matter or peculiar method to distinguish them, how can analytic philosophers pick one another out in the crowd when philosophers of all different stripes are jumbled together? If analytic philosophy lacks a matter or a method of its own why bother calling a philosopher analytic at all? You'll knock your head out trying to answer that question if what you're after is some strict definition, in terms of some essential, proprietary feature, for being an analytic philosopher. This makes appealing the suggestion that analytic philosophers resemble one another as the members of a family often do, by virtue of different features overlapping and criss-crossing, even if they don't all have the same nose. A related suggestion is that analytic philosophers share a common ancestry or common influences that allow us to establish an especial, albeit indirect relationship between them even if they diverge in other respects. ${ }^{1}$ But the fabric of history is too close knit. The overlapping threads of similarity and influence pull in too many directions.

${ }^{1}$ See P. M.S. Hacker, Wittgenstein's Place in Twentieth Century Analytic Philosophy, (Oxford Blackwell), 4-5, Hans Sluga, 'What Has History to Do with Me: Wittgenstein and Analytic Philosophy', Inquiry 41 (1998), 99-121, 107 and, for a more thoroughgoing development of these ideas, Hans-Johann Glock, What is Analytic Philosophy? (Cambridge: Cambridge University Press, 2008), 204-30. 
We need to take seriously the possibility that there is no such thing as analytic philosophy or such a thing as being an analytic philosopher. The beginning of the analytic period is usually identified as coinciding with the decline of idealism and the rise of Moore and Russell's realist philosophy at the end of the $19^{\text {th }}$ century and continuing until the present day. And indeed it's true that there are schools and movements, such as logical positivism and ordinary language philosophy, that can be identified as having emerged during this period and for certain purposes it can be enlightening to track their vicissitudes - although even in such favourable cases when we begin to look more closely what we discover is less of a school and more of a shoal. But what unity there is to be found of shared or overlapping presuppositions amongst these different schools is too diffuse to support significant historical speculation or explanation.

Here is a case of overlapping and criss-crossing in point. Even Moore and Russell shared many of their presuppositions with their idealist predecessors. Even though they were realists, Moore and Russell were only following in the footsteps of their idealist archrival, F.H. Bradley, when they set about analysing relational complexes of the form $a R b$, complexes wherein one thing is related to another, such as the fact that the cat is to the right of the mouse or the fact that this proton is more massive than that electron. Like Moore and Russell, Bradley had presupposed that an analysis of such a complex would reveal it to consist of two things $(a, b)$ and the relation $(R)$ that holds between them. But he could see no way of explaining how these diverse constituents could be put back together to form a unified complex or fact. It's not enough that they exist because that furnishes no guarantee that they actually embrace to form a complex. So it appears that to restore the unity of the complex $(a R b)$ which analysis destroyed, the relation $(R)$ must itself be related to the things $(a, b)$ it was supposed to relate. But this would appear to require a new connecting relation $\left(R^{*}\right)$ to relate the relation $(R)$ to the things it relates, a new relation about which the same questions can be raised as the old. It is not enough that the new relation exist; it $\left(R^{*}\right)$ must itself be related to the old relation $(R)$ and the things $(a, b)$ the old relation was originally supposed to relate. Bradley inferred that if we employ the machinery of things and relations we can't avoid being hurried off 'into the eddy of a hopeless process, since we are forced to go on finding new relations without 
end.'2 But Bradley was no less convinced that discursive thought inevitably employs the machinery of things and relations; we cannot avoid carving up the world that comes to us in terms of things that are adjacent to one another or inside one another, or events where one is before another, or one causes the other, and so on. So Bradley concluded that discursive thought must inevitably mislead us about the true character of reality because the very idea of a relation - the idea of something whose function it is to relate - is 'unintelligible'.

Russell found himself in exactly the same predicament, unable to account for the unity of relational complexes: 'when analysis has destroyed the unity' of a complex, Russell wrote, 'no enumeration of the constituents will restore' it. ${ }^{3} \mathrm{He}$ saw that the unity of a complex must somehow arise from the distinction between a relation that succeeds in relating the things it relates and a relation that does not; nonetheless, as Russell openly admitted, 'I do not know how to give a clear account of the precise nature of the distinction', of how it was possible for a relation to fulfil its proper function to relate. Where Russell differed from Bradley was with respect to the intelligibility of relational thought. Whilst Bradley denied it, because of where his argument had led him, Russell saw the absurdity of rejecting the intelligibility of all our thoughts about space, time and causation that constitute the larger part of science. So rather than deny the intelligibility of science, Russell preferred to live with the mystery of how relations fulfil their proper function: 'Even if I could see no way of answering the objections to relations raised (for example) by Mr. Bradley, I should still think it more likely than not that some answer was possible, because I should think an error in a very subtle and abstract argument more probable than so fundamental a falsehood in science'. ${ }^{4}$ So where Bradley had taken a modus ponens Russell took a modus tollens instead but the analyses they evoked were the same.

\footnotetext{
${ }^{2}$ See F.H. Bradley, Appearance and Reality (Oxford: Clarendon Press, 1897), 28, and 'Relations', in his Collected Essays: Vol. II, (Oxford: Clarendon Press, 1935), 630-76, 643.

${ }^{3}$ See Bertrand Russell The Principles of Mathematics (Cambridge: Cambridge University Press, 1903), §54.

${ }^{4}$ See Bertrand Russell 'Logical Atomism' in J.H. Muirhead (ed.) Contemporary British Philosophy (London: George Allen \& Unwin, 1924), 359-83, 378.
} 
Evidently the pre-analytic period didn't give way to the analytic as the Cretaceous to the Jurassic. When our history comes to be written it may even turn out that we have more in common with our predecessors than our successors. Whereas philosophers since Russell have conspicuously failed to supply an intellectually robust account of how relations fulfil their proper function, perhaps our successors may succeed. ${ }^{5}$ Of course this doesn't preclude our describing someone as an analytic philosopher in a loose and popular sense, as someone whose ideas and arguments are influenced by the work of one or other of the historical figures that as a matter of common practice it's become routine to describe as analytic.

\section{Confessions of an Analytic Philosopher}

In the loose and popular sense I am an analytic philosopher. The philosophers that have influenced me include prominent figures from the analytic pantheon: Moore, Russell, Wittgenstein, Quine, Davidson and Sellars. I cannot speak on behalf of other analytic philosophers today because there is no established peace amongst us. But the vision of philosophy that I hold true, which owes most to these great figures, isn't idiosyncratic.

I believe we are embodied creatures, occupants of an extended Universe of space and time that sweeps away before us. We share this Universe with an enormous number of other things, of one kind or another, standing in an extraordinary variety of relationships. ${ }^{6}$ I believe that there are better and worse ways for us to be orientated towards this Universe and towards each other - to think rigorously about the Universe and its denizens rather than fallaciously, to be erudite rather than ignorant, to behave well towards our fellows beings rather than badly. I believe it is possible to secure by reflection an understanding of what makes for a better rather than worse orientation. I also believe that it is possible to achieve by this route an understanding of how we may re-orientate ourselves towards the Universe and to each other to improve our situation. The task of acquiring such reflective understanding is one of theory construction. It is by

\footnotetext{
${ }^{5}$ Witness the failure of recent attempts to use modern truthmaker technology to account for the proper function of relations. See Fraser MacBride 'Relations and truthmaking', Proceedings of the Aristotelian Society 111 (2011), 161-79.

${ }^{6}$ See G.E. Moore's 1910 lecture, 'What is Philosophy?' in his Some Main Problems of Philosophy (London: George Allen \& Unwin, 1953), 1-27.
} 
constructing theories of what makes for a better (rather than worse) orientation and evaluating them that we are able to edge closer to understanding, whether theoretical or practical.

We rely perforce upon language to provide a medium within which to frame our theories - because of their subject matter they're too difficult to get into heads and keep there - and to enable us to lay the results of our cogitations before the tribunal of others. I also believe that the practice of analyzing the meanings of the words and phrases we use to construct our theories plays an exigent role in enabling us to achieve an understanding of what our theories are about. If we don't know what our words or phrases mean then we can't know what claim we're making about the world when we use them - we can't trust ourselves to have control over what we're saying. Nor can we have confidence that what one theory says that makes use of these words or phrases is better (or worse) than what another theory says. So don't trust philosophers who insist that they aren't interested in words but only the world (an unfortunate tendency amongst contemporary metaphysicians). If they don't get their words right they'll likely get the world wrong and lead the rest of us on a merry goose chase.

It is not a consequence of these remarks that the provision of a systematic account of the meanings of our words and phrases need be the foundation for all the rest of philosophy. Nor does it follow that we cannot think discursively about the world without saying so - that language enjoys priority over thought. ${ }^{7}$ To achieve world understanding theory construction is the game and theories need to be written down if creatures like us are to appreciate them. But what we mean by our uses of words and phrases when we construct a theory is often no more available for immediate comprehension than what we think is available for transient introspection. Distrust in the doctrine that minds are transparent to themselves has been a recurrent theme of twentieth century philosophy.

\footnotetext{
${ }^{7}$ Michael Dummett advanced both of these theses. See his 'Can Analytical Philosophy be Systematic and Ought it to Be?' in Truth \& Other Enigmas, London: Gerald Duckworth \& Co, 1978) 437-58, 441-2.Whilst I deny that a systematic theory of meaning need be conceived as a foundation for all the rest of philosophy, Dummett is entirely right that the production of such a theory, if there is such a thing to be had, would not only be a formidable intellectual achievement, but the theory itself would furnish an extraordinarily useful resource for enabling future philosophical research (for reasons that will become clear in the succeeding two paragraphs). I'd be straight online to buy one!
} 
The suspicion that languages aren't transparent to their speakers either, and stand in need of analysis if we're not to be misled, belongs to the same influential family of diaporeses. The view that the meaning of a natural kind term (say 'tiger') is determined by pointing at worldly specimens provides one reason for being doubtful that the meanings of words are invariably available for immediate comprehension - because if you don't know what the specimens are you won't be able to fathom from the text what the terms mean. But even a word whose meaning isn't determined by invoking worldly specimens has the potential to bear a significance that comes as a surprise even to its inventors.

The meaning of a word is determined by the contribution that it makes to the different contexts in which it occurs. But, as ordinary speakers of a language, we lack reflective oversight of all the different contexts in which a word occurs - all the different ways in which it is capable of combining with other kinds of expressions. ${ }^{8}$ As a consequence we are liable to misconceive the significance or function of a word when we venture an opinion off the cuff. This needn't jeopardize the practical use of language for ordinary transactions because our competent deployment of the expression may be otherwise unimpaired. But when we have before us a theory of the Universe and our orientation towards its constituents, it may make a critical difference to the success of the theory what function the word performs in enabling us to say something; whether, for example, the contribution of the word in question is to pick out a constituent of the Universe, or to perform one or another of a heterogeneous range of other functions, for example, to describe what the constituents of the Universe are like or to logically unite different claims into a single complex statement. So when we come to construct theories about what makes for a better (rather than worse) orientation to the Universe we can hardly neglect the task of scrupulously attending to the analyses - that facilitate reflective oversight - of the words and phrases we use to frame and convey what we deem to be our insights.

There is a sense in which the special disciplines (the sciences, humanities and others) can all be characterized as seeking to develop an understanding of what makes for a better rather than worse orientation but only within their own chosen fields - continually

\footnotetext{
${ }^{8}$ See Ludwig Wittgenstein, Tractatus Logico-Philosophicus (translated by C.K. Ogden with an introduction by B. Russell. London: Routledge \& Kegan Paul, 1922), 4.002.
} 
reflecting upon the aims and criteria proper to a discipline and updating them. Common sense represents the first proto-reflective efforts of the human species to construct a theory whose network of hypotheses, now embedded in ordinary language, would enable us to systematically understand and control the world surrounding us. This means common sense too can be characterized as the output of a (primordial and long-haul) effort to understand what makes for a better rather than worse orientation towards the world and each other. What distinguishes philosophy from these other reflective or protoreflective pursuits is the global or synoptic character of its commission. ${ }^{9}$ To philosophy falls the ultimate question: When does one orientation towards the Universe constitute an improvement upon another? We cannot begin to answer it until we have at least provisional answers to other questions that require us to occupy scarcely less cloud-capt an outlook: What kinds of thing inhabit the Universe? What distinguishes us amongst them? How are these various kinds of thing related to one another? But these questions cannot receive their definitive answers until the other disciplines that investigate the Universe from all their different points of view have completed their labours. So whilst it is continuous with common sense and all the other reflective disciplines, an especial eschatological burden is destined to fall to philosophy: to establish whether, or to what extent, the final outputs of physics, mathematics, psychology, political science and all the other special disciplines can be fused with common sense into one single periscopic vision of the Universe.

We cannot tell from our vantage point in history whether such a periscopic vision is possible. There may be no integrating the final outputs of the different disciplines and what common sense says. What can be said truly about the Universe may consist just in their loose assemblage - about such radically different items as numbers, duties, conscious experiences and neural firings. It is possible that what prevents our now seeing how these apparently categorically different items may be significantly assimilated is a combination of scientific ignorance and conceptual prejudices of which we are barely aware. Future scientific developments may not only dispel the factual ignorance that currently blinkers us but also help to bring such conceptual prejudices to light and lead us

\footnotetext{
${ }^{9}$ See Wilfrid Sellars, 'Philosophy and the Scientific Image of Man' in his Science, Perception and Reality (London: Routledge \& Kegan Paul, 1963), 1-40.
} 
to abandon them in favour of novel forms of thinking - as for example, $19^{\text {th }}$ century developments in the mathematics of the infinite revealed to be a prejudice the Aristotelian principle that a whole is invariably larger than any of its parts, a principle mathematicians and philosophers subsequently gave up..$^{10}$ But Aristotle couldn't have seen that one coming nor we can we foresee when such conceptual developments necessitated by the progress of science will overtake us.

Of course this does nothing to diminish the contemporary significance of philosophy for serving the progress of human knowledge by endeavoring to hasten the Epistemic End of Days, which means exposing relevant distinctions and connections, making explicit what has hitherto been implicit, elucidating what was previously taken for granted, seeking system and coherence amongst the myriad answers that the different disciplines have provisionally supplied to their proprietary questions.

\section{Why is philosophy so difficult?}

Kant famously declared in the Critique of Pure Reason (1787) that it 'remains a scandal to philosophy and human reason in general that the existence of things outside us must be accepted merely on faith [...] and that if anyone thinks good to doubt their existence we are unable to counter his doubts by any satisfactory proof'.${ }^{11}$ Over two centuries later it appears even more of a scandal to philosophy that we can't even be sure that we'd recognize a satisfactory proof of the external world if we saw one!

This is especially embarrassing for analytic philosophy (in the loose and popular sense) since the twentieth century endured more meta-philosophical soul searching than any other era of human history. Even the giants amongst us have been unable to furnish our subject with generally accepted methods of enquiry whereby results may be accepted or rejected according to commonly accepted criteria. It's not for want of trying. Quine tried to resolve philosophical problems by formalizing problematic ordinary language sentences in the language of logic. Strawson tried to resolve them by translating them back again into ordinary language. The successive failures of repeated efforts to set

${ }^{10}$ See Richard Dedekind, Essays on the Theory of Numbers (edited and translated by W.W. Beman, Chicago: Open Court Publishing Company, 1901), sec. v. ${ }^{11}$ See Immanuel Kant The Critique of Pure Reason (translated by N. Kemp Smith. London: Macmillan, 1929), Bxl. 
philosophy upon the path to convergence tempted others to a pessimistic induction, to conclude that philosophy keeps failing to achieve concessive results because it isn't about seeking the truth or stating the facts; philosophy bears some other kind of self-expressive significance, a form of conceptual poetry or the expression of obsessional doubts that require quasi-psychoanalytic treatment. ${ }^{12}$ But these ideas didn't stick either.

The historical contrast between the development of philosophy and the mature sciences is difficult to ignore. The sciences progress by incorporating the insights of preceding theories into the more expansive theories that succeed them - as, for example, the insights of wave optics were incorporated into electromagnetism. But philosophers have typically preferred a Sisyphean strategy, starting afresh as each generation declared a new dawn, each original philosopher seeing her task to begin again from the beginning. Analytic philosophers often reassure us that it really will be different this time because modern developments in mathematical logic, most conspicuously Frege's resolution of the logic of generality using the quantifier-variable notation, will lend to philosophy some of the exactitude and certainty of mathematics, enabling us to establish results that can be accepted as definitive by subsequent philosophers and used as a basis for further investigation. ${ }^{13}$ But even if God was able to create the world ex nihilo, we can't prove something from nothing. We always need to assume something else, even if we usually take this something else for granted because it's embedded in the rules of proof of the system we're using or how we apply them. Whether the techniques of mathematical logic will help stop the ball rolling back down the hill tomorrow remains to be seen.

What makes it so difficult to achieve a knowledgeable consensus in philosophy? This sounds like a substantial question but Russell, at one point, suggested that it isn't. He held that the mark of a philosophical problem is simply the fact that it has hitherto

${ }^{12}$ Compare W.V.O. Quine Word \& Object (Cambridge Mass.: MIT Press, 1960), 260-1, P.F. Strawson, 'Carnap's Views on Constructed Systems vs Natural Languages in Analytic Philosophy' in P. Schillp (ed.) The Philosophy of Rudolf Carnap, Library of Living Philosophers, Vol. XI (La Salle, Il.: Open Court, 1963), 503-18, 512-3, and Richard Rorty, Consequences of Pragmatism (Minneapolis: Minnesota University Press, 1982), xiii-xiv.

${ }^{13}$ See Bertrand Russell, 'On Scientific Method in Philosophy' in his Mysticism and Logic (New York: Longmans, Green \& Co. 1918), 96-120, and, for a more recent call to logicomathematical arms, see Timothy Williamson, 'Must Do Better' in P. Greenough \& M. Lynch Truth \& Realism (Oxford: Oxford University Press), 177-187. 
resisted solution by established means: 'I believe that the only difference between science and philosophy is, that science is what you more or less know and philosophy is what you do not know. Philosophy is that part of science which at present people choose to have opinions about, but which they have no knowledge about'. ${ }^{14}$ By Russell's lights the achievement of knowledgeable consensus deprives philosophy of the problems that previously consumed it, bequeathing them to science as soon as they become tractable. But Russell's suggestion about how to demarcate philosophy from science, whatever other attractions or flaws it may have, sheds no light whatsoever upon the deeper and more puzzling issue that remains. What is it about the problems with which philosophers have perennially concerned themselves - about rationality, knowledge, duty and all the rest - that has kept these problems so firmly rooted on the unknown side of the line, kept them philosophical in Russell's sense?

What makes these problems so resilient is the fact that they are general and pluriform. We cannot expect them to receive a definitive resolution until the Epistemic End of Days. There is no saying what makes an orientation towards the Universe rational or knowledgeable or morally commendable without having a grasp of the copious variety of different acts that count as such, an appreciation of the character of the agents that perform them and a digest of the polymorphic objects to which they are directed. But we cannot acquire such pervasive understanding without relying upon our grasp of other concepts that may also turn out to be problematic and drawing upon the results of other disciplines. And we don't know in advance what other questions will be thrown up by future developments within these disciplines or by the efforts of philosophers to integrate them into a unified scheme. But this isn't a scandal to philosophy. It's a consequence of the encompassing and compounding character of the problems with which philosophy deals that their resolution requires of us a synoptic understanding. Because we cannot foresee completely what discoveries the special disciplines will make, what conceptual hurdles we will have to overcome, what hitherto prized intellectual possessions will need to be abandoned along the wayside, what unprecedented questions will need to be

${ }^{14}$ See B. Russell 'Lectures on the Philosophy of Logical Atomism (1918-1919)' reprinted in his Logic and Knowledge: Essays 1901-1950, edited by R.C. Marsh (London: George Allen \& Unwin, 1956), 177-281, 281. Originally published in The Monist, XXVIII (1918), 495-527, XXIX (1919), 32-63, 190-222, 345-80. 
answered, we cannot expect to establish a method today that will be guaranteed to work to the satisfaction of everyone tomorrow. We cannot expect progress in philosophy to be linear because until the Epistemic End of Days the problems of philosophy will remain open ended in a manner that surpasses any other discipline - because philosophy is the discipline that's ultimately there for the sake of putting the rest together.

\section{Why does history matter to analytic philosophy?}

Philosophy is an ultra-speculative discipline so it should come as no surprise that the history of philosophy has been a haphazard one. This doesn't mean that the history of philosophy isn't worth reading, that it's just a compendium of errors and confusions. Original philosophers have always made bold and arresting hypotheses that have contributed, one way or another, to the body or to the organization of human knowledge. Russell's theory of descriptions was especially significant for the development of analytic philosophy because it showed how the logical significance of a sentence might be belied by its superficial grammatical appearance; hence the praise that Russell won from Wittgenstein, 'Russell's merit is to have shown that the apparent logical form of the proposition need not be its real form'.${ }^{15}$ Analytic philosophers and theoretical linguists have subsequently built upon this insight.

Of course there are errors and confusions to be found in the works of historical philosophers too; but more what we discover are thinkers that have expanded or elaborated upon their systems until they have pushed against the intelligible boundaries of speculation, to a point where we can no longer comfortably follow them. This is exactly what we should expect of the great figures of such an ultra-speculative discipline. And it's what makes them worthwhile for us to study. Because philosophy is so speculative - because we lack the established methodology of a mature science to ensure cumulative progression - we cannot expect to have superseded the contributions of our predecessors. For all we know their views may lie closer to the truth in important respects than our own. Our business as philosophers remains to speculate because that is how philosophy contributes to the development of human knowledge. By studying the philosophers of the past we enable and refine and inspire speculations of our own. It may

${ }^{15}$ Op cit, note 5, 4.0031 
even be the case that because their world-views were less cluttered and confused by the hyperbolic development of other disciplines, philosophers of the past came closer than we have done to attaining the synoptic perspective that constitutes the End of philosophy. Similarly Shakespeare belonged to a time simpler than our own but so far from this rendering his works obsolete their uncluttered character contributes to the especial lucidity of his insights into human nature.

Recognizing that philosophy is ultra-speculative so the works of the great philosophers don't have a definite use-by date doesn't require us to have confidence in what has been called the 'analytic history of philosophy' - the view which Williams characterized as 'encouraging us to read something written by Plato as though it had come out in Mind last month' ${ }^{16}$ Williams is rightly wary of a Whig view of history whereby philosophy has now progressed out of darkness into the light to acquire what is now a definitive list of questions for philosophers to answer and techniques for answering them. He's right that there is no such list available to us. But once we recognize that the articles that appeared in Mind last month are just further contributions to a form of ultraspeculative enquiry for which there is no established scientific methodology there should be no objection to reading one of Plato's dialogues alongside them. Williams recounts with approval a passage from Collingwood's autobiography in which Collingwood casts scorn upon the ridiculous view that because ' $\delta \varepsilon 1$ ' in Greek is translated by 'ought' in English, Greek ethics and Kantian theories of moral obligation must be about the same thing: 'It was like having a nightmare about a man who had got it into his head that $\tau \rho ı \eta \rho \eta \varsigma$ was the Greek for "steamer", and when it was pointed out to him that descriptions of triremes in Greek writes were at any rate not very good descriptions of steamers, replied triumphantly, “That's just what I say. These Greek philosophers ... were terribly muddle-headed and their theory of steamers is all wrong"'. ${ }^{17}$ But it doesn't follow from the fact that ancient philosophers differed from us with respect to some normative projects that they didn't share at a deep level some of our concerns. Otherwise we would be unable to interpret the corpus of ancient writings as featuring philosophical

${ }^{16}$ See Bernard Williams, 'Philosophy as a Humanistic Discipline', Philosophy, 75, 477 96, 478 .

${ }^{17}$ See R.G. Collingwood, An Autobiography (Oxford: Oxford University Press, 1939), 64. 
arguments in the first place. It is this shared background that makes is still possible for Plato to share his extraordinarily fruitful speculations with us.

Understanding that philosophy is ultra-speculative not only helps guard us against the 'analytic history of philosophy' Williams dismisses. If philosophical progress cannot be expected to be linear then even present day philosophers cannot be expected to be the generation that succeeded where earlier generations failed. Knowledge of the history of philosophy can often perform a useful role in enabling us to recognize when the maneuvers undertaken by present-day philosophers are regressive. This is possible because it is sometimes the case that our predecessors were ahead of us.

It has been an abiding insight of analytic philosophy that thought and language aren't transparent, don't wear their significance upon their sleeves, but stand in need of analysis - a recent variation upon the recurrent philosophical theme that we need to get behind appearances to tell the ultimate truth about reality. But Kripke's celebrated remarks about essentialism rely for their effectiveness upon our relinquishing this hardwon insight. In his lectures on naming and necessity, Kripke invited us to consider whether a given table, composed of molecules, could be this very table without being composed of molecules. Kripke didn't offer an argument one way or another. Instead he introspected before reporting back to us: 'Certainly there is some feeling that the answer to that must be 'no'. At any rate, it's hard to imagine under what circumstances you would have this very object and find that it is not composed of molecules' ${ }^{18}$ Later in his lectures, Kripke invited us to consider whether a given person could have originated from a different sperm and egg. Again it was the results of introspective psychology that supplied Kripke with his answer: 'It seems to me that anything coming from a different origin would not be this object' ${ }^{19}$ On this basis Kripke concluded that material objects must have their origins essentially. But it cannot be assumed that the beliefs made available for immediate introspection, or the linguistic embodiments that we use to express them, wear their significance on their sleeves.

Our intuitions may come easily to us - we may be able to blurt them out without having to think too hard. But it hardly follows that such beliefs enjoy some privileged

\footnotetext{
${ }^{18}$ See Saul Kripke, Naming and Necessity (Oxford: Blackwell, 1980), 47.
}

${ }^{19} \mathrm{Op}$ cit, note $13,113$. 
epistemological status that entitles us to derive from them substantial conclusions about the antics of material objects outside of us. Whatever these judgments mean - and that remains to be established - any number of contributory factors may be responsible for holding them psychologically in place, factors that have no especial connection to their veracity. It is only when we have investigated the sustaining factors that surround these beliefs that we will be entitled to draw conclusions about essentialism from their occurrence. Because Kripke willfully refrained from such an investigation his approach was regressive.

Of course there are cases in which it is reasonable to suppose that there is a reliable connection between the intuitions of an ordinary subject and the subject matter at hand. The clearest example of this concerns the grammar of natural language. People's intuitions about what combinations of words are grammatical are partially constitutive of the very language they speak. Their spontaneous reactions to combinations of words tells us something about the structure of the practical ability speakers of a given language share. Ultimately if we do not share the grammatical intuitions of other speakers we recognize that they speak a different dialect from us. It is for this reason that linguists take the intuitions of ordinary speakers with maximal seriousness. But things that exist outside of us don't have this kind of constitutive connection to our assured beliefs about them. So there is no especial reason to think that the intuitions that are readily elicited from ordinary subjects about the essences of material objects are reliable indicators concerning whether material objects have their constitutions or origins essentially.

Russell and Quine already understood that even our most assured and unreflective beliefs cannot be taken for granted. They recognized that thought and language aren't transparent so even here there is a pressing question of appearance and reality; but a significant minority of subsequent philosophers following Kripke have evidently forgotten. Russell and Quine knew that our most keenly felt common sense convictions about the ordinary things that we encounter in our immediate environment are shot through with theory. Quine recognized that 'Even our primordial objects, bodies, are already theoretical'; whilst Russell credited commonsense to 'prehistoric metaphysicians'. C.D. Broad made a related point concerning our capacity to be positively misled by reflections that come readily to us when they are couched in the 
idiom of natural language: 'The language in which we... talk about material things and events were formed unwittingly in prehistoric times to deal in a practical way with a kind of normalized extract from out total perceptual experience. It was formed in utter ignorance of a whole range of relevant physical, physiological and psychological facts. It would surely be nothing short of a miracle if it were theoretically adequate, and if it were not positively misleading in some of its implications'. Indeed even Russell's idealist predecessors, including Bradley himself, appreciated that we only think about the world through a network of judgments we make about it: "In every case that which is called the fact is in reality a theory". ${ }^{20}$ This is another notable point of continuity between them.

To return to the present, the intuitions to which Kripke et al appeal aren't sources of theoretically untainted, pristine evidence of what the Universe and its denizens are like. To switch metaphors, each intuition is just the visible tip of an iceberg, an iceberg whose massive substructure, concealed from view beneath the waves, isn't only theoretical but also perceptual, practical and physiological. Recent Kripke-inspired moves to elicit 'intuitions' as an oracular source of philosophical knowledge represents a abandonment of this hard-won insight, a loss which a more than passing acquaintance with the history of philosophy ought to have prevented. ${ }^{21}$

FRASER MACBRIDE (fraser.macbride@glasgow.ac.uk) is Professor of Logic and Rhetoric at the University of Glasgow. His recent publications include 'Truthmakers' (Stanford Encyclopaedia of Philosophy, http://plato.stanford .edu/entries/truthmakers/, 2013), 'How involved do you want to be in a non-symmetric relationship?' (Australasian Journal of Philosophy, 2013), and 'For keeping truth in truthmaking' (Analysis, 2013).

${ }^{20}$ See W.V.O. Quine, 'Things and Their Place in Theories' in his Theories and Things (Cambridge, Mass.: Harvard University Press, 1981), 1-23, 20, B. Russell, 'The Relation of Sense-Data to Physics' in his Mysticism and Logic (New York: Longmans, Green \& Co, 1918), 140-72, 149, C.D. Broad "Philosophy and 'Common Sense"' in G.E. Moore: Essays in Retrospect (London: George Allen \& Unwin, 1970), 203 and F.H. Bradley, "The Presuppositions of Critical History", Collected Essays: Volume I (Oxford: Clarendon Press, 1935), 1-70, 17.

${ }^{21}$ I am grateful to audiences at the Royal Institute of Philosophy in London, a meeting of SEFA in Madrid and a Graduate Reading Party held by the University of Glasgow at the Burn. I would also like to thank Helen Beebee, Renée Bleau, Tyler Burge, Jane Heal, Ken Gemes, Sacha Golob, Frédérique Janssen-Lauret, Mike Martin, Kevin Mulligan, Chris Pincock and Alan Weir for subsequent discussion. 